\title{
Chorea as the Neurological Symptom of Delayed Encephalopathy After Carbon Monoxide Intoxication in a Child
}

The Neurohospitalist 2016, Vol. 6(3) 130-131 (C) The Author(s) 2016 Reprints and permission: sagepub.com/journalsPermissions.nav DOI: $10.1177 / 1941874416628606$ nhos.sagepub.com

(S)AGE

\author{
Muhammad Ubaidulhaq, MD', Young Ah Lee, MD², \\ and Huiyuan Jiang, $\mathbf{M D}^{\prime}$
}

\section{Keywords}

chorea, delayed encephalopathy, carbon monoxide (CO) intoxication

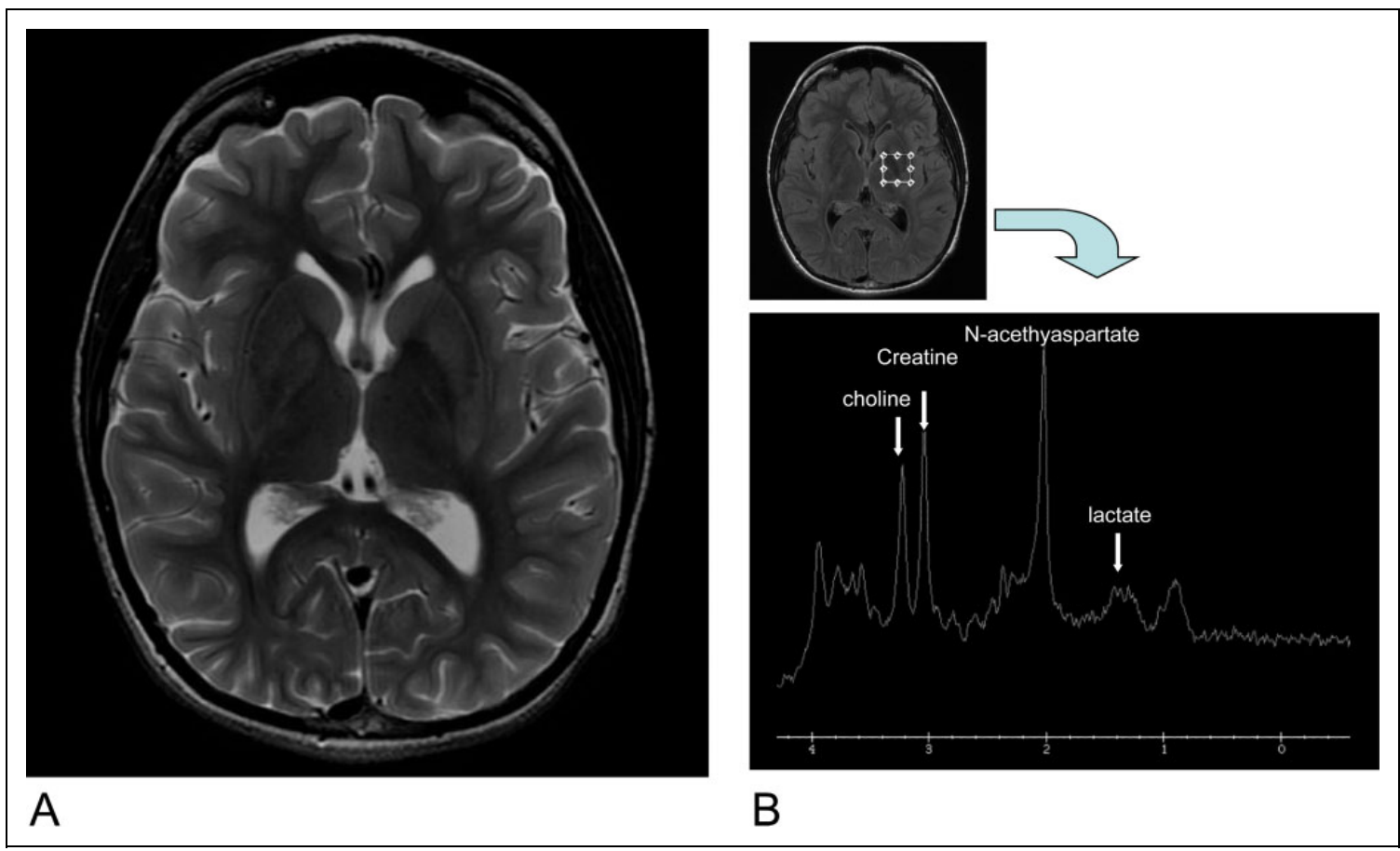

Figure I. A, T2-weighted axial sequence of brain magnetic resonance imaging (MRI) shows hyperintensities in the bilateral basal ganglia. The signal changes are greater involving the left caudate and putamen and greater involving the right globus pallidus. B, Brain magnetic resonance spectroscopy (MRS) with voxel over the left basal ganglia shows small lactate peaks.

A 10-year-old boy presented to the emergency department with abnormal movements 8 days after he was rescued from a house fire. At the scene, he was comatose and was found to have soot in his airway. He had an elevated carboxyhemoglobin level (24.5\%). He received mechanical ventilation with $100 \%$ oxygen for 40 hours. He showed rapid recovery in mental status and was discharged home. Eight days after the injury, he developed tremors, dystonia, and chorea involving his face and all extremities (Video). Brain magnetic resonance imaging showed T2 hyperintensity in the caudate, putamen, and globus pallidus bilaterally, and magnetic resonance spectroscopy showed lactate peaks in the basal ganglia (Figures $1 \mathrm{~A}$ and $\mathrm{B}$ ).

\footnotetext{
'Division of Pediatric Neurology, Department of Pediatrics, Children's Hospital of Michigan, Detroit, MI, USA

${ }^{2}$ Beaumont Pediatric Neurology Center, Beaumont Hospital, Royal Oak,
} MI, USA

Corresponding Author:

Huiyuan Jiang, Division of Pediatric Neurology, Department of Pediatrics, Children's Hospital of Michigan, 390 I Beaubien Blvd. Detroit, MI 4820I, USA. Email: hjiang@med.wayne.edu 
Trihexyphenidyl improved his dystonia and tremor within a month, but the chorea worsened. After he discontinued trihexyphenydyl, chorea gradually resolved. Eight months after the injury, he is still experiencing emotional, behavioral, and academic problems as well as intermittent urinary incontinence.

Delayed encephalopathy after carbon monoxide (CO) intoxication is characterized by mental deterioration, gait disturbance, speech disorder, seizure, and incontinence preceded by an asymptomatic period of variable duration (from 2 to 40 days) following recovery from the acute stage. ${ }^{1}$ Additionally, destructive lesions of basal ganglia may result in movement disorders. Parkinsonism has been reported to occur in $9.5 \%$ of $\mathrm{CO}$-poisoned patients. ${ }^{2}$ The incidence of chorea after $\mathrm{CO}$ poisoning is known to be rare. Its duration ranges from days to months, and it is usually alleviated through the use of neuroleptics and aggravated by anticholinergics. ${ }^{3}$

\section{Declaration of Conflicting Interests}

The authors declared no potential conflicts of interest with respect to the research, authorship, and/or publication of this article.

\section{Funding}

The authors received no financial support for the research, authorship, and/or publication of this article.

\section{References}

1. Kwon OY, Chung SP, Ha YR, Yoo IS, Kim SW. Delayed postanoxic encephalopathy after carbon monoxide poisoning. Emerg Med J. 2004;21(2):250-251.

2. Choi IS. Parkinsonism after carbon monoxide poisoning. Eur Neurol. 2002;48(1):30-33.

3. Song IU, Chung SW. Chorea as the first neurological symptom of delayed encephalopathy after carbon monoxide intoxication. Intern Med. 2010;49(11):1037-1039. 